\title{
Deciding the care of severely malformed or dying infants
}

\author{
A G M Campbell Department of Child Health, University of Aberdeen and \\ R S Duff Department of Pediatrics, Yale University School of Medicine, New Haven, Connecticut, USA
}

\section{Authors' abstract}

Suffering patients (when able), grieving families and compassionate physicians have always sought the least detrimental alternative while deciding care in the face of tragedy. Modern medical technology has brought great benefits to patients but has blurred traditional concepts of life and death and created new dilemmas for practising doctors. While this technology has given doctors great control over living and dying, their dominance in critical decision making is being challenged. More and more their decisions are liable to public and legal scrutiny, intense publicity by the news media and exploitation by lobbyists with opposing aims.

Increasing pressure of this kind may deflect the physician from his primary responsibility to patients and their families.

For infants with gross malformations or a distressing terminal illness we believe that the parents and their doctors must be allowed primary decisional power even if the chosen course of action involves the death of the infant. Choices for death should be permitted but only after suitable family and professional consultation. Some general guidelines are suggested. As these situations are so varied and so complex, much latitude in decision-making should be expected and tolerated.

'Practices that have been invisible are becoming visible. Problems that were thought to be individual will be seen to be recurrent and widely shared. Half-baked semi-informed enthusiasts will see in the new medicine the arrival of the millenium; half-baked semi-informed troglodytes will denounce each scientific advance as blasphemy. Tempers will rise and denunciation will fill the air. ${ }^{1}$

\section{The ethical dilemma}

Some view a painful terminal illness or a life severely compromised through handicap as fates worse than death itself, especially when suffering is exaggerated or prolonged by treatment that can be no more than palliative. Adults, within certain limits and with the guidance of their doctors, may decline life-prolonging treatment and accept an earlier death as a preferable alternative. Treatment is stopped and 'nature is allowed to take its course'. Sedatives and analgesics may be used to alleviate suffering although it is accepted that through their use life may be shortened. This course of action has come to be known as 'passive euthanasia', an unfortunate term but one that describes a practice that, while controversial, appears to be acceptable to the majority of doctors, ${ }^{2}$ and as far as can be judged, the public at large. 'Active euthanasia', the intentional termination of the life of one human being by another, even by request and to relieve suffering, is forbidden by law and may be viewed as manslaughter or murder, although often euphemistically called 'mercy killing'. With modern technological control over life and death in actual medical practice the distinction may be extremely blurred. Also it can be argued that there is no moral or legal difference whatsoever between 'letting die' and 'killing'. ${ }^{3}$ An obsessive persistence with this distinction or adoption of the rigidity of the absolutist tends to conceal the real issues and does little to protect patients and families from exploitation by proponents of conflicting ideologies. Too often debates become polarised and over-simplified as conflicts between the 'quality' and the 'sanctity' of life.

Newborn infants and young children pose special problems. For them these fundamental decisions can only be made by proxy. Traditionally, doctors alone made decisions for or against treatment, often without any reference to parental views in the well-meaning but mistaken belief that they were sparing grief-stricken parents an unbearable additional burden. In recent years the importance of joint consultation has been stressed and some believe it appropriate for doctors and the infant's family (usually the parents) to decide a course of action even if this involves the death of the infant. ${ }^{4,5}$ This view is being challenged, principally by lawyers and 'professional ethicists' who argue that as the principles involved are moral and not scientific, doctors are not qualified and parents have no right to make these decisions. ${ }^{6,7,8}$ They suggest that more public discussion is necessary and that a court may be the appropriate place to decide these issues so that the rights of the individual infant may be more adequately protected. Public discussion to date would seem to indicate considerable support for leaving the decision-making to the parents and the doctors primarily involved in the tragedies.

Inevitably, some doctors and some parents may join in a covert conspiracy to deny the right of a 
defective child to live or die. Depending on their own views, doctors may consider it their duty always to prolong life as long as possible or they may give up too soon believing that the cause is lost. They may actively intervene to postpone or accelerate death. Two fundamental principles which govern the attitude of doctors to their patients are in conflict. First, that it is a doctor's duty to relieve suffering, even at the risk of causing death, and, second, that human life itself is sacred and that doctors have a duty to prolong life at all costs. Just as doctors have widely varying attitudes to the tragedies of abnormal births, so do parents. They too have mixed motives. They may seek the death of the child to obtain relief from their suffering; the tensions of caring for a handicapped child, and their anxieties about the future. Some parents will accept seriously abnormal infants without resentment and will love and care for them unstintingly. Others, usually having major commitments to understandably competing interests, cannot accept the situation and conflict and disruption will result if it is forced upon them. What may be unifying, constructive and fulfilling for one family may be extremely destructive to another. Parents have varying capacities for giving unstinting, unselfish continuous care even to normal infants. They may be unable to cope with the increased physical and emotional demands of caring for the abnormal.

Bad decisions are possible but many safeguards against bad choices are already in existence and it can be argued that the courts are unlikely to be any better in dealing with these enormously complex problems. Almost without exception parents grow to cherish a newborn infant as part of themselves during the last trimester of pregnancy whether they wanted the baby originally or not. They have the most intimate knowledge of family realities, and have the most to lose or gain. Thus, the challenge of deciding which course to take is an agonising one for the doctor and the family. Unfortunately, not facing the issue at all is the easier course to take. 'Since families and patients must live with the problem one way or another in any case, the physician's failure to face the issues may constitute a victimising abandonment of patients and their families in time of greatest need.' 4

\section{Taking the decision}

While many doctors may be involved in the care of these infants, one doctor must assume leadership. $\mathrm{He}$ or she can be designated the responsible doctor. The identity of this individual usually will be selfevident. When caring for an infant or child in hospital the responsible doctor will usually be a paediatrician or paediatric surgeon. He or she will be responsible for assessing the patient and the family, for coordinating the activities of other specialists, and for communicating with the pareni about the diagnosis, prognosis and major recom mendations for a course of action. While it is sug gested that the doctor must assume leadership it is important to stress the order of primary decisiona power in these extremely difficult situations. adult practice the patient's opinions are of prines importance. For infants we believe that the paren must have primary decisional power although the responsible physician usually shares or assumes this in order to help the parents with the burden. Much will depend on the close involvement of the famity with a doctor they can trust. As important $\overrightarrow{a s}$ medical leadership are the strong positive roleg played by nurses and social workers. Working as team all must ensure that the decisions are based on complete information and are consistent with the finest traditions of caring for patients and thein families. As someone who is likely to know the family well, the general practitioner may be able to play an extremely important part in assessing the true feelings of the family members. Doctors less directly involved, administrators and lawyers for example may give wise counsel but lack intimatse knowledge of patients and families and the 'uniqueo ness' of each of these tragedies and do not have to live with the consequences of the choices. The also have institutionalised responsibilities and special interests that may be in conflict with the views and values of patients and families.

Can parents in a state of shock and bereavement following the birth of a defective child really unde? stand the issues and take part in such decisions? In our opinion, usually they can, provided the time is allowed for explanations and questions; and for discussion with other family members and othe्ष 'counsellors'. Information must be given in words that they understand so that the benefits and limitations of any proposed treatments are undes stood clearly. The responsible doctor must be particularly sensitive to the feelings and views of the parents, but parents must never be left with the feeling that they alone are making the maj decisions. The doctor must focus primarily on the needs and rights of the individual infant but it Is unrealistic to consider the problems of the infat in total isolation from the family. In addition to careful medical evaluation the doctor must cowsider and be sensitive to the family's social, cultura, religious and economic background; the emotiongl state and attitudes of family members; the obligation to siblings and others. The doctor must seek a solution that for this infant and family seens just, humane and loving, based on the principle \&f individualism.

\section{Options for care}

At the present time the various available option can be categorised as follows: 
Group I Maximum treatment without qualification. The outlook from successful treatment is likely to be good. All available methods of treatment and life support should be applied as indicated.

\section{Group 2 Limited treatment.}

Patients in this group are not likely to benefit overall from applying all available treatments. The emphasis should be on the alleviation of patient suffering. Life should not be prolonged through the application of inappropriate methods of resuscitation.

Group 3 Withdrawal of life-sustaining treatment.

Many of these patients are dying and for them it is imperative that suffering be alleviated and dying not be unnecessarily prolonged. The responsible physician should ensure that the patient's (if known) and family's wishes are heeded if at all possible. For example, the family may wish to have their child at home during the terminal phase. With proper guidance, both the child and family may benefit greatly.

\section{Disagreement}

If there is disagreement among members of staff to the extent that the responsible doctor is unable to present an agreed plan of care to the parents, an open discussion with the parents may help to resolve the conflict. The parents may wish to seek the views and advice of other members of the family, a clergyman or others.

If the parents disagree with the proposed course of action their wishes must be reviewed in the light of:

I) The diagnosis;

2) The likely outcome for the child, with or without treatment; including an assessment of the 'quality of life' for the child and the family;

3) The degree of certainty of prognosis;

4) The likelihood of psychological burdens for the child and his family in later years.

Parents may seek legal help at any time to resolve conflicts of this kind. Likewise, doctors (or others involved in the child's care) can seek court assistance if they consider that the parents (or doctors) have made a choice that is detrimental to the child's best interests.

As we have emphasised before, we believe that there is little substance in the philosophical 'slippery slope' argument when applied to such tragedies affecting a newborn infant. ${ }^{9}$ The danger is great when governments or other institutions choose death for minor difficulties or for the 'good of society' or the convenience of the family. ${ }^{10}$ The above decisions and choices can be made only by those who care most for the patient and must bear the consequences.

\section{References}

${ }^{1}$ Manning, Bayless (1970). Legal and policy issues in the allocation of death. The Dying Patient. Edited by Brim, O G, Freeman, $\mathbf{H}$ E, Levine, $S$ and Scotch, N A. New York: Russell Sage Foundation, pp 255-256.

${ }^{2}$ Crane, Diana (1975). The Sanctity of Social Life: Physicians Treatment of Critically Ill Patients. New York: Russell Sage Foundation.

${ }^{3}$ Rachels, James (1975). Active and passive euthanasia. The New England fournal of Medicine, 292, 78-80.

${ }^{4}$ Duff, R S and Campbell, A G M (1973). Moral and ethical dilemmas in the special care nursery. The New England fournal of Medicine, 289, 890-894.

${ }^{5}$ Ellis, H L (1974). Parental involvement in the decision to treat spina bifida cystica. British Medical fournal, $x, 369-372$.

${ }^{6}$ Robertson, J A and Fost, N (1976). Passive euthanasia of defective newborn infants: Legal considerations. The fournal of Pediatrics, 88, 883-889.

'Kennedy, Ian (1978). Letter to The Times, 9 January.

${ }^{8}$ Ramsey, Paul (1978). Ethics at the Edges of Life: Medical and Legal Intersections. New Haven and London: Yale University Press.

'Duff, R S and Campbell, A G M (1976). On deciding the care of severely handicapped or dying persons: with particular reference to infants. Pediatrics, 57, 487-493.

${ }^{10}$ Alexander, Leo (1949). Medical Science under Dictatorship. The New England fournal of Medicine, 241, 39-47. 